\title{
A novel APOC2 gene mutation identified in a Chinese patient with severe hypertriglyceridemia and recurrent pancreatitis
}

\author{
Jingjing Jiang ${ }^{1+}$, Yuhui Wang ${ }^{2+}$, Yan Ling ${ }^{1}$, Abudurexiti Kayoumu², George Liu² and Xin Gao ${ }^{1 *}$
}

\begin{abstract}
Background: The severe forms of hypertriglyceridemia are usually caused by genetic defects. In this study, we described a Chinese female with severe hypertriglyceridemia caused by a novel homozygous mutation in the APOC2 gene.

Methods: Lipid profiles of the pedigree were studied in detail. LPL and HL activity were also measured. The coding regions of 5 candidate genes (namely LPL, APOC2, APOA5, LMF1, and GPIHBP1) were sequenced using genomic DNA from peripheral leucocytes. The ApoE gene was also genotyped.

Results: Serum triglyceride level was extremely high in the proband, compared with other family members. Plasma LPL activity was also significantly reduced in the proband. Serum ApoCll was very low in the proband as well as in the heterozygous mutation carriers. A novel mutation (c.86A > CC) was identified on exon 3 of the APOC2 gene, which converted the Asp codon at position 29 into Ala, followed by a termination codon (TGA).

Conclusions: This study presented the first case of ApoCll deficiency in the Chinese population, with a novel mutation c.86A > CC in the APOC2 gene identified. Serum ApoCll protein might be a useful screening test for identifying mutation carriers.
\end{abstract}

Keywords: Hypertriglyceridemia, APOC2 gene, Mutation

\section{Background}

The severe forms of hypertriglyceridemia or chylomicronemia are usually caused by genetic defects. However, in most patients, it remains a challenge to define the underlying cause. The clinical features of chylomicronemia include: recurrent episodes of pancreatitis, hepatosplenomegaly, lipemia retinalis, and eruptive xanthomata. So far, mutations in five genes have been found responsible for a portion of these patients, namely lipoprotein lipase (LPL), apolipoprotein A-V (APOA5), apolipoprotein C-II (APOC2), glycosylphosphatidylinositol-anchored highdensity lipoprotein-binding protein 1 (GPIHBP1) and

\footnotetext{
* Correspondence: zhongshan_endo@126.com

${ }^{\dagger}$ Equal contributors

${ }^{1}$ Department of Endocrinology and Metabolism, Zhongshan Hospital, Fudan

University, Shanghai, China

Full list of author information is available at the end of the article
}

lipase maturation factor 1 (LMF1) [1]. Mutations in the LPL gene are the most common, while mutations in the APOC2 and LMF1 genes are rare.

The Apolipoprotein CII (ApoCII) protein circulates in the blood as a surface component of chylomicrons, VLDL, and HDL [2]. It plays an important role in triglyceride metabolism as a cofactor for LPL, the rate limiting enzyme for hydrolysis and removal of triglycerides from chylomicrons and VLDL. ApoCII deficiency leading to chylomicronemia was first described in 1978 and was recognized as an autosomal recessive disease $[3,4]$. Patients with ApoCII deficiency have marked alterations of triglyceride metabolism, leading to elevated fasting triglycerides, chylomicrons, and VLDL [4].

To our knowledge, mutation of the APOC2 gene has never been described in the Chinese population. Here we describe a novel homozygous mutation of the APOC2 
gene, leading to truncation and loss of the entire Cterminal, in a Chinese female patient with severe hypertriglyceridemia and recurrent episodes of pancreatitis. The patient had a favorable response to orlistat treatment.

\section{Methods}

\section{Case description}

A 31-year old female was referred to our hospital due to persistent hypertriglyceridemia. Her mother recalled that once she was ill at 2 years old and at a local hospital, her blood was "white". Later she recovered and didn't follow up. At the age of 19, she experienced first episode of acute pancreatitis after a feast. During that episode, serum triglyceride level was unknown. Two years later, she was attacked by pancreatitis again during pregnancy and her serum triglyceride level was above the $22.5 \mathrm{mmol} / \mathrm{L}$ upper limit at a local hospital. She recovered later and gave birth to a healthy baby boy. After delivery she was treated with fibrates, niacins and statins, to which she responded poorly.

On admission, no eruptive cutaneous xanthomas or lipemia retinalis were found. Routine laboratory tests, with the exception of plasma lipids (see results), were within the reference range. Abdominal Computed Tomography (CT) scan revealed slight hepatosplenomegaly. Despite high level of TG, her liver fat accumulation was relatively mild, quantified as $11 \%$ by liver Magnetic Resonance Spectroscopy (MRS). Her physical and mental development appeared normal. Her parents were consanguineous (cousins). Her younger sister and brother, as well as her 10-year old son all appeared normal, without history of dyslipidemia or pancreatitis.

\section{Plasma lipid profile analysis}

Blood samples were collected from the proband and her immediate family members after an overnight fast. Serum TG, T-C, HDL-C, LDL-C and non-HDL-C levels were measured enzymatically on an automatic analyzer (Hitachi High-Tech, 7600-120, Japan). The measurement of serum lipoproteins, including ApoAI(DiaSys, Germany), ApoB (DiaSys, Germany), ApoCII(Sekisui, Japan) and ApoE(Sekisui, Japan) was performed by immunoturbidimetric assays on an automatic analyzer (Hitachi HighTech, 7600-120, Japan).

\section{Postheparin plasma LPL activity assay}

Postheparin plasma (10 min after iv injection of $50 \mathrm{IU} / \mathrm{kg}$ heparin) was collected and total lipase activity was determined by incubation of the plasma at $37{ }^{\circ} \mathrm{C}$ for $60 \mathrm{~min}$ with $3 \mathrm{H}$-triolein emulsion substrate prepared as described previously [5], with or without heat-inactivated rat serum as source of exogenous ApoCII. Lipase activity was mainly for hepatic lipase (HL) activity after LPL activity was inhibited with $1 \mathrm{M} \mathrm{NaCl}$ on ice for $30 \mathrm{~min}$. LPL activity was calculated by subtracting HL activity from total lipase activity ( $1 \mathrm{mU}$ corresponds to $1 \mathrm{nmol}$ free fatty acid generated per minute).

\section{Analysis of candidate genes}

Genomic DNA was extracted from peripheral blood leucocytes by a standard procedure. All exons, including the intron/exon boundaries of APOC2, LPL, LMF1, APOA5, and GPIHBP1 genes were PCR-amplified and sequenced as previously described [1]. Genotyping of the APOE gene was also performed by TaqMan assays following manufacturer's instructions.

The study was approved by the ethics committee of Zhongshan hospital, Fudan University. Informed consents were obtained from each subject participating in the study after full explanation of the purpose and nature of all procedures used.

\section{Results}

\section{Serum lipid and lipoproteins}

On admission, the proband's serum TG, HDL-C and LDL$\mathrm{C}$ were $17.42 \mathrm{mmol} / \mathrm{L}, 0.67 \mathrm{mmol} / \mathrm{L}$ and $0.36 \mathrm{mmol} / \mathrm{L}$, respectively. The fasting serum after standing overnight at $4{ }^{\circ} \mathrm{C}$ had diffuse lipemia throughout and a chylomicron layer on top (Fig. 1b), typical of Fredrickson type 5 hyperlipidemia, suggesting high levels of both chylomicron and VLDL. Five days after strict diet control, serum TG, HDL$\mathrm{C}$ and LDL-C were $12.41 \mathrm{mmol} / \mathrm{L}, 0.49 \mathrm{mmol} / \mathrm{L}$ and $0.48 \mathrm{mmol} / \mathrm{L}$, respectively (Table 1 ). Though detectable, ApoCII was very low in the proband's serum, whereas serum ApoE level was sharply increased, consistent with the increased level of serum triglyceride (Table 1).

All the immediate family members of the proband had normal lipid levels, including TG, TC, HDL-C, LDL-C and non-HDL-C. All family members had lower level of ApoB, except the proband's father, whose LDL-C was close to the upper limit. Interestingly, though detectable, the ApoCII level was low in all family members (Table 1 ).

The proband was maintained on strict low-fat diet and later was advised to take orlistat $60 \mathrm{mg}$ tid. Though she didn't strictly follow the suggested regimen, her TG declined gradually below $10 \mathrm{mmol} / \mathrm{L}$ and later further improved within $5 \mathrm{mmol} / \mathrm{L}$ during the past one year. In a recent follow up, serum TG level was $4.5 \mathrm{mmol} / \mathrm{L}$ (Table 1).

\section{Postheparin plasma LPL activity}

Plasma postheparin LPL activity of the proband (homozygous) was significantly lower than her mother (heterozygous) and the normal control (wild type). In contrast, the addition of exogenous ApoCII (rat serum) lead to a dramatic increase of the proband's LPL activity (Table 2). 


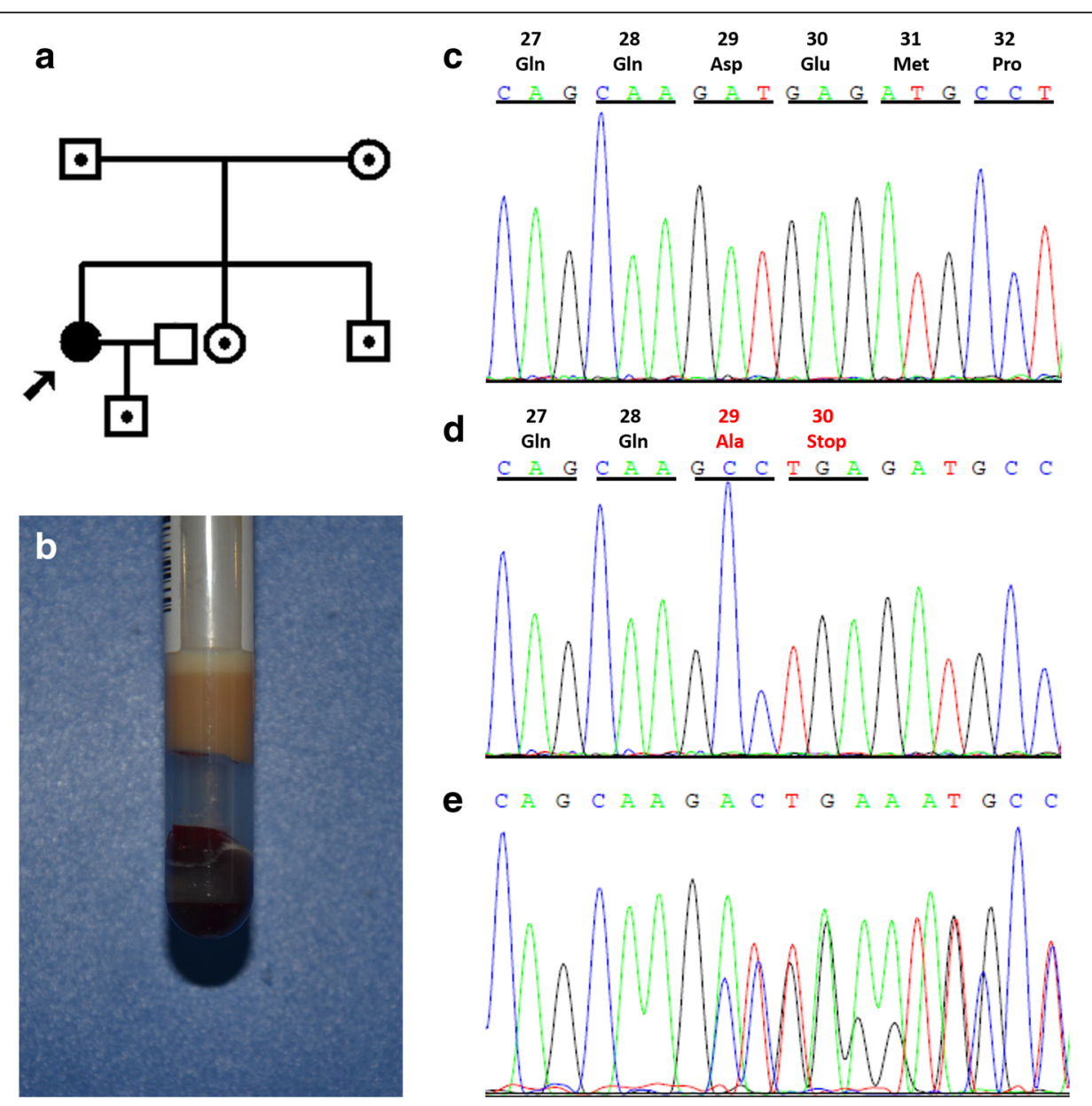

Fig. 1 Pedigree and DNA sequence analysis of the family. a Pedigree of the family with APOC2 gene mutation. b Opacitas serum with a chylomicron layer on the top after placed overnight at $4{ }^{\circ} \mathrm{C}$. c, d, e Electropherogram of a wild type control (c), the proband with homozygous APOC2 gene mutation (d) and her sister with heterozygous APOC2 gene mutation (e)

\section{Sequencing of candidate genes}

A homozygous mutation on exon 3 of the APOC2 gene in the proband was identified: c.86A was replaced by 2 consecutive $\mathrm{Cs}(\mathrm{c} .86 \mathrm{~A}>\mathrm{CC})$, which converts the Asp codon at position 29 into Ala, followed by a termination codon (TGA) (Fig. 1d). The presence of this mutation was confirmed by sequencing at both directions. This mutation was not identified in 100 Chinese unrelated healthy controls, ruling out SNP. A heterozygous mutation was observed in the proband's parents, her younger

Table 1 Lipid profile of the pedigree

\begin{tabular}{|c|c|c|c|c|c|c|c|c|}
\hline & Father & Mother & Proband & Proband $^{\mathrm{a}}$ & Sister & Brother & Son & Reference \\
\hline Age & 51 & 50 & 31 & 31 & 27 & 23 & 8 & \\
\hline $\mathrm{TC}(\mathrm{mmol} / \mathrm{L})$ & 5.05 & 4.12 & 3.74 & 2.81 & 4.11 & 3.72 & 4.69 & $<5.2$ \\
\hline $\mathrm{TG}(\mathrm{mmol} / \mathrm{L})$ & 1.3 & 0.83 & 12.41 & 4.5 & 0.87 & 0.51 & 1.18 & $0.6-1.7$ \\
\hline $\mathrm{HDL}-\mathrm{C}(\mathrm{mmol} / \mathrm{L})$ & 1.35 & 1.56 & 0.49 & 0.53 & 1.82 & 1.28 & 2.03 & $>1.04$ \\
\hline LDL-C(mmol/L) & 3.11 & 2.18 & 0.48 & 0.91 & 1.9 & 2.21 & 2.12 & $<3.12$ \\
\hline non-HDL-C(mmol/L) & 3.7 & 2.56 & 3.25 & 2.28 & 2.29 & 2.44 & 2.66 & $2.08-4.14$ \\
\hline ApoAl(g/L) & 1.39 & 1.43 & 1.11 & 0.97 & 1.43 & 1.16 & 1.76 & $1.1-1.9$ \\
\hline ApoB(mg/dl) & 0.98 & 0.69 & 0.6 & 0.52 & 0.6 & 0.56 & 0.67 & $0.75-1.5$ \\
\hline ApoCII(g/L) & 0.4 & 0.4 & 0.35 & $<0.2$ & 0.3 & 0.8 & 0.6 & $1.6-4.2$ \\
\hline ApoE(mg/L) & 37 & 30 & 76 & 53 & 32 & 24 & 33 & $29-53$ \\
\hline
\end{tabular}

arecent follow-up 
Table 2 Post heparin plasma lipase activity (mU/ml)

\begin{tabular}{lrlrl}
\hline & Total & $\mathrm{HL}$ & $\mathrm{LPL}$ & Exogenous ApoCII \\
\hline proband & 32.2 & 20.2 & 12.0 & without rat serum \\
mother & 74.7 & 32.7 & 42.0 & \\
control & 64.7 & 23.3 & 41.4 & \\
proband & 75.3 & 18.1 & 57.2 & with rat serum \\
mother & 142.5 & 22.0 & 120.5 & \\
control & 155.8 & 23.0 & 132.8 & \\
\hline
\end{tabular}

sister, brother and her son (Fig. 1e). Further subcloning and sequencing confirmed that they were all heterozygous mutation carriers. No mutation was identified on exons, as well as the intron/exon boundaries of LPL, LMF1, APOA5, and GPIHBP1 genes. The ApoE genotype of all family members, including the proband, was $\varepsilon 3 / \varepsilon 3$.

\section{Discussion}

ApoCII, together with ApoCI and ApoCIII, belongs to the ApoC family [2]. In humans, ApoCII is mainly produced by the liver. The APOC2 gene is located on chromosome 19 and encodes an 101-residue peptide [6]. Cleavage of the $\mathrm{N}$-terminal 22-residue signal peptide yields the mature human ApoCII protein, which containing 3 amphipathic helices. The $\mathrm{N}$-terminal is responsible for lipid-binding and the C-terminal helix is responsible for activating LPL [6]. So far only 14 deleterious APOC2 gene mutations have been described [7-20] (Table 3). All mutations resulted in loss of functional $\mathrm{C}$-terminal, being unable to activate LPL.

The present mutation, which we designated ApoC$\mathrm{II}_{\text {Shanghai, }}$ was predicted to translate into a truncated 29 amino acid peptide devoid of the C-terminal. The ApoCII level was very low in the proband's serum possibly because either the protein itself was unstable and rapidly degraded, or the protein couldn't be properly secreted. Similar ApoCII levels have been found in patients homozygous for other mutations (Table 3). Reports on the serum ApoCII protein levels of heterozygous relatives have been inconsistent. While ApoCII ${ }_{\text {Toronto }}$ [3], ApoCII Wakayama [14], ApoCII ${ }_{\text {Auckland }}$ [19], ApoCII hamburg [21] and the current ApoCII Shanghai heterozygous relatives had lower serum ApoCII levels, ApoCII Padova heterozygotes had ApoCII levels similar to unaffected family members [22]. Clinically, serum ApoCII levels are usually elevated in patients with hypertriglyceridemia. So low ApoCII combined with high TG levels might suggest ApoCII deficiency and the presence of low ApoCII levels in direct relatives even further increases this probability. In the present study, immunoturbidimetric assay was used to determine serum ApoCII levels. Although not as sensitive as radioimmunoassay, this method is less technically demanding and more applicable. It is also cost-effective and suitable for screening.

Paradoxically, both excess and deficiency of ApoCII are associated with hypertriglyceridemia. Transgenic mice overexpressing human ApoCII had marked hypertriglyceridemia and the ApoCII levels positively correlated with TG levels, due to impaired clearance and consequent accumulation of VLDL [23]. Recently APOC2 loss-of-function mutant mice were generated using zinc finger nucleases, which exhibited high TG levels as expected [24]. For patients with ApoCII deficiency, recurrent hyperlipidemic pancreatitis remains the major threat, while cardiovascular consequences are generally unremarkable. Due to uptake of chylomicrons by macrophages, hepatosplenomegaly is

Table 3 Summary of APOC2 gene mutations

\begin{tabular}{|c|c|c|c|c|}
\hline Type & Nucleotide change & Amino acid change & APOC2 level & Ref. \\
\hline promoter & c. $-86 \mathrm{~A}>\mathrm{G}$ & $\mathrm{N} / \mathrm{A}$ & undetectable & 18 \\
\hline missense & c. $1 A>G$ & M1V(ApoCII Paris) & undetectable & 11 \\
\hline missense & c. $142 \mathrm{~T}>\mathrm{C}$ & W48R(ApoCII Wakayama) & undetectable & 14 \\
\hline missense & c. $281 \mathrm{~T}>\mathrm{C}$ & L94P(ApoCII Hongkong) & n.d. & 15 \\
\hline nonsense & c. $177 C>$ G & Y59*(ApoCll Bari) & undetectable & 9 \\
\hline nonsense & C. $177 C>A$ & Y59*(ApoCll Padova) & very low & 12 \\
\hline nonsense & c. $10 \mathrm{C}>\mathrm{T}$ & R4*(ApoCll Paris2) & undetectable & 17 \\
\hline nonsense & $c .255 C>A$ & Y85*(ApoCII Auckland) & undetectable & 19 \\
\hline deletion & c.270delT & frameshift(ApoCII Toronto) & undetectable & 8 \\
\hline deletion & c.118delG & frameshift(ApoCII Nijmegen) & undetectable & 13 \\
\hline deletion & c.70delC & frameshift(ApoCII Jap/ven) & undetectable & 20 \\
\hline gross-del & Loss of $E 2,3,4$ & untranslated(ApoCII Tuzla) & undetectable & 16 \\
\hline insertion & c.274dupC & frameshift(ApoCII St.Michael) & n.d. & 7 \\
\hline splicing & IVS2 ds G-C +1 & C.55 + 1G > C(ApoCll Hamburg) & very low & 10 \\
\hline del-ins & $C .86 \mathrm{~A}>\mathrm{CC}$ & frameshift(ApoCII Shanghai) & very low & \\
\hline
\end{tabular}


common, though fatty liver is actually mild, as in the present case.

Currently therapeutic interventions in ApoCII deficiency are still limited. Transfusion of normal plasma can provide temporarily sufficient ApoCII to activate LPL and normalize lipid profile [4]. Though not applicable as a routine therapy, this is still of clinical significance, because in contrast to LPL deficiency, ApoCII deficient patients could benefit from fresh plasma transfusion in case of acute hyperlipidemic pancreatitis. Another ideal cure is a biologically active synthetic ApoCII peptide. According to one report, the reduction in plasma triglycerides after a single injection persisted for 13-20 days [25]. Recently a novel bi-helical ApoCII mimetic peptide also showed promising effects in a mouse model [24]. Unfortunately, due to the rarity of the disease, commercialized synthetic peptides are not available in the clinic. Impaired clearance of chylomicron is the major cause of hypertriglyceridemia in ApoCII deficiency. Orlistat, an agent for obesity, inhibits gastric and pancreatic lipases in the lumen of the gastrointestinal tract to reduce the digestion and absorption of dietary fat, resulting in less intestinal chylomicron synthesis [26]. A small study including 5 patients with type V hyperlipidemia showed the addition of orlistat to conventional therapy resulted in a further $35 \%$ reduction in triglycerides [27]. Interestingly, in the present case, orlistat markedly improved serum triglyceride compared with strict diet control alone. Though taken intermittently, orlistat brought the triglyceride level down to below $5 \mathrm{mmol} / \mathrm{L}$ and maintained well without rebound.

\section{Conclusion}

In conclusion, we identified a novel mutation in the APOC2 gene. This was also the first case of APOC2 gene mutation diagnosed in the Chinese population. In patients with severe hypertriglyceridemia, serum ApoCII might be a good screening marker for identifying mutation carriers. Orlistat might be effective and worth trying in homozygous patients, though synthetic ApoCII peptides are to be expected in future.

\section{Competing interests}

The authors declare no competing interests.

\begin{abstract}
Authors' contribution
$J J$ and YW carried out the molecular genetic study and drafted the manuscript. YL diagnosed the proband. AK measured the LPL and $H L$ activity. GL coordinated the research. XG planned the study protocol, coordinated the research, revised and prepared the final version of the manuscript. All authors read and approved the final manuscript.
\end{abstract}

\section{Acknowledgments}

This work was supported by the National Natural Science Foundation of China (Grant No. 81270933), and the Major State Basic Research Development Program of China (2012CB524906 to X.G. We thank Shouxiong Huang (University of Cincinnati) for advice and suggestions on the manuscript.

\section{Author details}

'Department of Endocrinology and Metabolism, Zhongshan Hospital, Fudan University, Shanghai, China. Institute of Cardiovascular Science, Peking University and Key laborotory of Molecular Cardiovascular Science, Ministry of Education, Beijing, China.

Received: 9 October 2015 Accepted: 29 December 2015

Published online: 16 January 2016

\section{References}

1. Surendran RP, Visser ME, Heemelaar S, Wang J, Peter J, Defesche JC, et al. Mutations in LPL, APOC2, APOA5, GPIHBP1 and LMF1 in patients with severe hypertriglyceridaemia. J Intern Med. 2012;272:185-96.

2. Jong MC, Hofker MH, Havekes LM. Role of ApoCs in lipoprotein metabolism: functional differences between $\mathrm{ApoC1}$, ApoC2, and ApoC3. Arterioscler Thromb Vasc Biol. 1999;19:472-84.

3. Cox DW, Breckenridge WC, Little JA. Inheritance of apolipoprotein C-II deficiency with hypertriglyceridemia and pancreatitis. N Engl J Med. 1978;299:1421-4.

4. Breckenridge WC, Little JA, Steiner G, Chow A, Poapst M. Hypertriglyceridemia associated with deficiency of apolipoprotein C-II. N Engl J Med. 1978;298:1265-73.

5. Ding Y, Wang Y, Zhu H, Fan J, Yu L, Liu G, et al. Hypertriglyceridemia and delayed clearance of fat load in transgenic rabbits expressing human apolipoprotein CIII. Transgenic Res. 2011;20:867-75.

6. Fojo SS, Law SW, Brewer Jr HB. Human apolipoprotein C-II: complete nucleic acid sequence of preapolipoprotein C-II. Proc Natl Acad Sci U S A. 1984;81:6354-7.

7. Connelly PW, Maguire GF, Little JA. Apolipoprotein CIISt. Michael. Familial apolipoprotein Cll deficiency associated with premature vascular disease. J Clin Invest. 1987;80:1597-606.

8. Cox DW, Wills DE, Quan F, Ray PN. A deletion of one nucleotide results in functional deficiency of apolipoprotein CII (apo CII Toronto). J Med Genet. 1988;25:649-52.

9. Crecchio C, Capurso A, Pepe G. Identification of the mutation responsible for a case of plasmatic apolipoprotein CII deficiency (Apo CII-Bari). Biochem Biophys Res Commun. 1990;168:1118-27.

10. Fojo SS, Beisiegel U, Beil U, Higuchi K, Bojanovski M, Gregg RE, et al. Donor splice site mutation in the apolipoprotein (Apo) C-II gene (Apo C-IIHamburg) of a patient with Apo C-II deficiency. J Clin Invest. 1988; 82:1489-94.

11. Fojo SS, de Gennes JL, Chapman J, Parrott C, Lohse P, Kwan SS, et al. An initiation codon mutation in the apoC-II gene (apoC-II Paris) of a patient with a deficiency of apolipoprotein C-II. J Biol Chem. 1989;264:20839-42.

12. Fojo SS, Lohse P, Parrott C, Baggio G, Gabelli C, Thomas F, et al. A nonsense mutation in the apolipoprotein C-IIPadova gene in a patient with apolipoprotein C-II deficiency. J Clin Invest. 1989;84:1215-9.

13. Fojo SS, Stalenhoef AF, Marr K, Gregg RE, Ross RS, Brewer Jr HB. A deletion mutation in the ApoC-II gene (ApoC-II Nijmegen) of a patient with a deficiency of apolipoprotein C-II. J Biol Chem. 1988;263:17913-6.

14. Inadera H, Hibino A, Kobayashi J, Kanzaki T, Shirai K, Yukawa S, et al. A missense mutation (Trp 26->Arg) in exon 3 of the apolipoprotein Cll gene in a patient with apolipoprotein Cll deficiency (apo CII-Wakayama). Biochem Biophys Res Commun. 1993;193:1174-83.

15. Lam CW, Yuen YP, Cheng WF, Chan YW, Tong SF. Missense mutation Leu72Pro located on the carboxyl terminal amphipathic helix of apolipoprotein C-II causes familial chylomicronemia syndrome. Clin Chim Acta. 2006;364:256-9.

16. Okubo M, Toromanovic A, Ebara T, Murase T. Apolipoprotein C-II : a novel large deletion in APOC2 caused by Alu-Alu homologous recombination in an infant with apolipoprotein C-II deficiency. Clin Chim Acta. 2014;438C:148-53.

17. Parrott CL, Alsayed N, Rebourcet R, Santamarina-Fojo S. ApoC-IIParis2: a premature termination mutation in the signal peptide of apoC-II resulting in the familial chylomicronemia syndrome. J Lipid Res. 1992;33:361-7.

18. Streicher R, Geisel J, Weisshaar C, Avci H, Oette K, Muller-Wieland D, et al. A single nucleotide substitution in the promoter region of the apolipoprotein C-II gene identified in individuals with chylomicronemia. J Lipid Res. 1996;37:2599-607. 
19. Wilson CJ, Priore Oliva C, Maggi F, Catapano AL, Calandra S. Apolipoprotein C-II deficiency presenting as a lipid encephalopathy in infancy. Ann Neurol. 2003:53:807-10.

20. Xiong WJ, Li WH, Posner I, Yamamura T, Yamamoto A, Gotto Jr AM, et al. No severe bottleneck during human evolution: evidence from two apolipoprotein C-II deficiency alleles. Am J Hum Genet. 1991;48:383-9.

21. Beil FU, Fojo SS, Brewer Jr HB, Greten H, Beisiegel U. Apolipoprotein C-\| deficiency syndrome due to apo C-IIHamburg: clinical and biochemical features and Hphl restriction enzyme polymorphism. Eur J Clin Invest. 1992;22:88-95

22. Gabelli C, Bilato C, Santamarina-Fojo S, Martini S, Brewer Jr HB, Crepaldi G, et al. Heterozygous apolipoprotein C-II deficiency: lipoprotein and apoprotein phenotype and Rsal restriction enzyme polymorphism in the Apo C-IIPadova kindred. Eur J Clin Invest. 1993;23:522-8.

23. Shachter NS, Hayek T, Leff T, Smith JD, Rosenberg DW, Walsh A, et al. Overexpression of apolipoprotein Cll causes hypertriglyceridemia in transgenic mice. J Clin Invest. 1994:93:1683-90.

24. Sakurai T, Sakurai A, Vaisman BL, Amar MJ, Liu C, Gordon SM, et al. Creation of ApoC-II mutant mice and correction of their Hypertriglyceridemia with an ApoC-II mimetic peptide. J Pharmacol Exp Ther. 2015.

25. Baggio G, Manzato E, Gabelli C, Fellin R, Martini S, Enzi GB, et al. Apolipoprotein C-II deficiency syndrome. Clinical features, lipoprotein characterization, lipase activity, and correction of hypertriglyceridemia after apolipoprotein C-II administration in two affected patients. J Clin Invest. 1986;77:520-7.

26. Heck AM, Yanovski JA, Calis KA. Orlistat, a new lipase inhibitor for the management of obesity. Pharmacotherapy. 2000;20:270-9.

27. Wierzbicki AS, Reynolds TM, Crook MA. Usefulness of Orlistat in the treatment of severe hypertriglyceridemia. Am J Cardiol. 2002;89:229-31.

\section{Submit your next manuscript to BioMed Central and we will help you at every step:}

- We accept pre-submission inquiries

- Our selector tool helps you to find the most relevant journal

- We provide round the clock customer support

- Convenient online submission

- Thorough peer review

- Inclusion in PubMed and all major indexing services

- Maximum visibility for your research

Submit your manuscript at www.biomedcentral.com/submit

) Biomed Central 